\title{
Editorial
}

\section{Past, present and future!}

Well, Gold Bulletin's 30th year was an eventful one! The impact of the fall in the gold price was felt even in the editorial office and we had to 'trim the sails' and realign our priorities. This led to the deferment of publication of the planned 2 issues, Vol 30 (3) \& (4)*, in the latter half of the year. My sincere apologies to you all for the inconvenience that this caused and my heartfelt thanks to the many

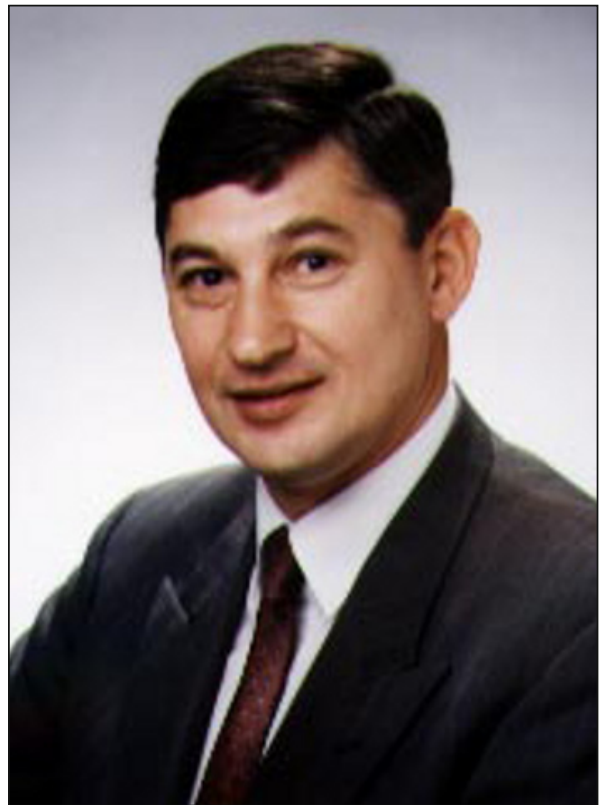
readers who wrote to me expressing dismay, sympathy and support. This tells me that you value the journal and that it fills an important need in your information requirements.

So what of the future? Well, the good news is that World Gold Council remains committed to the publication of Gold Bulletin and its objectives. We plan to publish 4 issues of Volume 31 this year, starting with this issue. We are re-aligning our editorial policy to place more emphasis on technical articles, particularly the timely publication of new topical research results, at the expense of the literature abstracts and patents digest. We wish to clear the backlog of articles awaiting publication.

We are also going 'live' on the Internet with this issue. You will find it on the Council's website: http://www.gold.org - I welcome your comments on this innovation.

Now for the bad news. Well, actually there isn't any, apart from the fact that we are reconsidering how important literature abstracts and patents are to the journal. With space at a premium (and costs under tight control), we believe that technical papers and reviews should take precedence. Maybe we should drop the abstract/patent section or maybe we will just put them on the Internet page rather than in the printed edition. Would you be prepared to pay for such a service? What do you think? Tell us your views.
This issue contains 5 excellent papers covering a range of disciplines and applications. I hope that you enjoy them. I particularly hope that they stimulate new ideas and applications. Enjoy this issue. I know its been worth the wait!

Don't forget to tell us your views. You can reach me via telephone (+44 $171 \quad 930 \quad 5171)$, fax $(+441718396561)$ or E-mail (chris.corti@wgclon.gold.org). All these electronic devices and systems for communication, incidentally, rely on gold in some form as a critical constituent. Despite what certain bankers and economists may believe, gold is an essential component of our daily lives and demand continues to outpace new metal supply from the mines. Our motto should be the same as the Olympic athletes: "Go for Gold!"

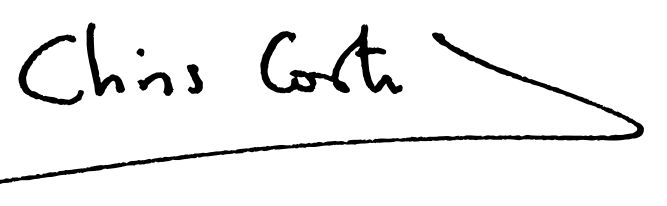

Chris Corti

Editor

* Footnote: The index to Volume 30 will be combined with that for Volume 31 and appear in part 4 at the end of the year. 